\title{
Neuraxial Dexmedetomidine: Wonder Drug or Simply Harmful
}

\author{
Sohan Lal Solanki ${ }^{1, *} ;$ Vipin Kumar Goyal $^{2}$ \\ ${ }_{1}^{1}$ Department of Anesthesiology, Critical Care and Pain, Tata Memorial Hospital, Mumbai, India \\ ${ }^{2}$ Department of Anesthesiology and Critical Care, Mahatma Gandhi Medical College and Hospital, Jaipur, India \\ ${ }^{*}$ Corresponding author: Sohan Lal Solanki, Department of Anesthesiology, Critical Care and Pain, Tata Memorial Hospital, Mumbai, India. Tel: +91-2224177053, Fax: +91-2224146937, \\ E-mail:me_sohans@yahoo.co.in
}

Received: August 9, 2014; Revised: August 31, 2014; Accepted: September 21, 2014

Keywords: Dexmedetomidine; Anesthesia; Analgesia

In current anesthesia practice, neuraxial anesthesia is a major method among all anesthesia modalities. The most frequently performed neuraxial blocks are consecutively subarachnoid, epidural, and caudal blocks. Major indications are intraoperative anesthesia and analgesia, postoperative analgesia, analgesia for vaginal delivery, and management of chronic pain. For these purpose, local anesthetics (LA) are widely used alone or in combination with adjuvants. Adjuvants are mixed with LA to shorten the onset of action, increase the quality of block, increase the duration of anesthesia and analgesia, and to decrease the dose of LA. Benzodiazepines (e.g. midazolam), opioids (e.g. morphine, fentanyl, and sufentanil), -adrenergic agonists (e.g. epinephrine or phenylephrine), ketamine, and 2-adrenergic receptor agonists (e.g. clonidine or dexmedetomidine [DEX]) are adjuvants of common use. Mechanisms of action are also different. Out of these, 2-adrenergic receptor agonists are relatively newer and their uses are increasing. DEX, a dextrorotatory S-enantiomer of medetomidine, is an 2-adrenergic receptor agonist with the chemical structure being (S)-4[1-(2,3-dimethylphenyl) ethyl]-3H-Imidazole (Figure 1).

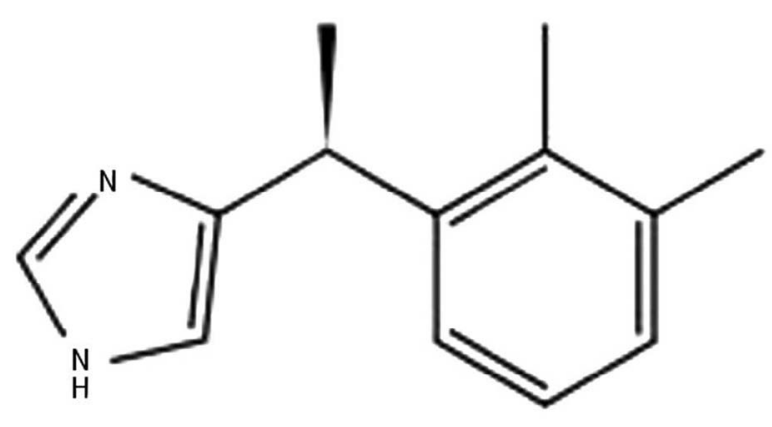

Figure 1. Chemical Structure of Dexmedetomidine

Like clonidine, DEX also acts on both 1 and 2 receptors. The 1 to 2 receptors binding ratio of 1:1620 makes it a highly selective 2 agonist in comparison to clonidine. Hence, the advantage of DEX over clonidine is decreased incidence of adverse effects due to involvement of 1 receptors (1). In 1999, the Food and Drug Administration (FDA) approved DEX use for short-term sedation and analgesia ( $<24$ hours) in the intensive care units (ICU). In perioperative period, intravenous infusion of DEX acts as an anxiolytic and analgesic that blunts sympathetic response to laryngoscopy and intubation (2-4), decreases sympathetic response and emergent reaction on extubation with no delay in recovery or prolonged sedation $(5,6)$, and decreases the need for anesthetic agents (intravenous and inhalational), cardiovascular stabilization, neuroprotection, renoprotection, and no or minimal respiratory depression, reduced postoperative shivering (7). In critically ill patients, DEX is a useful sedative agent with analgesic properties, hemodynamic stability, and ability to recover respiratory function in mechanically ventilated patients facilitating early weaning. Other claimed advantages are reduced ICU stay, decreased duration of ventilation, and reduced agitation $(8,9)$. Although FDA has not approved DEX as an adjuvant in neuraxial blocks, it is widely used and is still in use in anesthesia practice as an adjuvant in regional anesthesia for both epidural and intrathecal modalities. Most of these trials, which had used DEX in intrathecal and epidural block, were conducted with or without prior approval of Institutional Ethics Committees. FDA and Drug Controller General of India (DCGI) do not approve "off-label use" of DEX as intrathecal or epidural adjuvant. Although outcome of most of these studies is favorable for its use as an adjuvant for neuraxial anesthesia, approval by FDA and DCGI is desirable for its uncontroversial use in anesthesia practice. Adding an adjuvant to the LA in subarachnoid or epidural space needs complete information regarding its specific gravity, $\mathrm{pH}$, and compatibility as well as stability of the LA and adjuvant mixture; at present, no study has done or at least

Copyright (C) 2015, Iranian Society of Regional Anesthesia and Pain Medicine(ISRAPM). This is an open-access article distributed under the terms of the Creative Commons Attribution-NonCommercial 4.0 International License (http://creativecommons.org/licenses/by-nc/4.0/) which permits copy and redistribute the material just in noncommercial usages, provided the original work is properly cited. 
reported such information. In neuraxial anesthesia, DEX mediates its analgesic effects via spinal 2 receptors by depressing the release of C-fiber neurotransmitters and by hyperpolarization of postsynaptic dorsal horn neurons (10). Binding of 2 adrenoceptor agonists to motor neurons in the dorsal horn explains the motor effect of DEX. When used as an adjuvant to LA for neuraxial block, DEX leads to (10-14):

1. Reduced onset time of sensory and motor block,

2. increased duration of sensory block,

3. delayed motor regression,

4. prolonged postoperative analgesia and reduced total dose of analgesic,

5. Delayed need of first rescue analgesic,

6. Decreased postoperative shivering.

Effects are usually dose dependent. Until now, there is no specific recommended dose of DEX for this purpose. Dose can be varied from 3 to $15 \mu \mathrm{g}$ as an adjuvant to LA in spinal anesthesia. Solanki et al. stated that in comparison to clonidine $(50 \mu \mathrm{g})$, equipotent dose of intrathecal DEX $(5 \mu \mathrm{g})$ significantly prolonged postoperative analgesia (10). When compared to other adjuvants (fentanyl, magnesium sulfate, or buprenorphine), DEX showed prolonged postoperative analgesia with delayed and decreased need of rescue analgesics (11-13). For caudal epidural block, 1 to $2 \mu \mathrm{g} / \mathrm{kg}$ of DEX along with bupivacaine led to prolonged analgesia without significant side effects $(14,15)$. Moreover, use of epidural DEX significantly decreases the anesthetic requirements, prevents awareness during anesthesia, and improves intraoperative oxygenation and postoperative analgesia $(16,17)$. DEX along with LA for epidural analgesia during labor pains shows good maternal satisfaction without deleterious effect on uteroplacental circulation and newborns outcome (18). In a review and meta-analysis of perineural DEX, Abdallah et al. (19) showed an association between intrathecal or epidural DEX, as adjuvant to LA, and onset and duration of sensory and motor blockade; moreover, the time to first analgesic request was prolonged. They also mentioned that these results might be due to publication bias because of the source studies may or may not reflect less stringent Institutional Review Board and/or editorial board policies. DEX has also been used as an adjuvant in peripheral nerve blocks and has shown to prolong the sensory and motor block duration (20). The most common reported adverse effects are bradycardia and hypotension. Bradycardia due to DEX is resistant to atropine and higher doses are needed; although rare, even cardiac arrest might occur. Reported fatal complications of DEX were mainly related to its intravenous use as infusion in the elderly and in patients with cardiac disease $(21,22)$. Hypotension is due to decrease in central sympathetic outflow. When a large dose of DEX is used, it is preceded by hypertensive episode due to stimulation of $-2 \mathrm{~B}$ receptors. Klinger et al. (23) in a retrospective analysis of 15656 patients concluded that there was no significant difference in the overall incidence of intraoperative hypoten- sion (5.3\% in DEX group, 6\% in control group) or bradycardia ( $0.4 \%$ in both groups); however phenylephrine or atropine were more required in DEX group (23\% vs. $15 \%$; $\mathrm{P}<0.0001)$. DEX should not be used as a sole anesthetic for neuraxial anesthesia. Konakci et al. (24), in their study on rabbits, observed that when epidural DEX was administered without LA, it would induce neurotoxicity (evidence of demyelination of the oligodendrocytes in the white matter in DEX group) in doses as high as $6.1 \mu \mathrm{g} / \mathrm{kg}$. None of the human randomized studies have used DEX doses $>0.2 \mu \mathrm{g} / \mathrm{kg}$ for spinal adjuvant and $>1 \mu \mathrm{g} / \mathrm{kg}$ for epidural adjuvant. In addition, intrathecal DEX has shown a neuroprotective effect similar to methylprednisolone $(25,26)$, and no long-term and irreversible harmful effect of neuraxial DEX has been reported yet.

In conclusion, DEX is a good LA adjuvant that can hasten the onset and prolong the duration of sensory and motor blockade when used in intrathecal or epidural block and appears to be safe; however, there are insufficient safety data to support the use of neuraxial DEX in the clinical setting.

\section{References}

1. Kalso EA, Poyhia R, Rosenberg PH. Spinal antinociception by dexmedetomidine, a highly selective alpha 2-adrenergic agonist. Pharmacol Toxicol.1991;68(2):140-3.

2. Bloor BC, Ward DS, Belleville JP, Maze M. Effects of intravenous dexmedetomidine in humans. II. Hemodynamic changes. Anesthesiology. 1992;77(6):1134-42.

3. Ebert TJ, Hall JE, Barney JA, Uhrich TD, Colinco MD. The effects of increasing plasma concentrations of dexmedetomidine in humans. Anesthesiology. 2000;93(2):382-94.

4. Bekker A, Sturaitis M, Bloom M, Moric M, Golfinos J, Parker E, et al. The effect of dexmedetomidine on perioperative hemodynamics in patients undergoing craniotomy. Anesth Analg. 2008;107(4):1340-7.

5. Turan G, Ozgultekin A, Turan C, Dincer E, Yuksel G. Advantageous effects of dexmedetomidine on haemodynamic and recovery responses during extubation for intracranial surgery. Eur J Anaesthesiol. 2008;25(10):816-20.

6. Aksu R, Akin A, Bicer C, Esmaoglu A, Tosun Z, Boyaci A. Comparison of the effects of dexmedetomidine versus fentanyl on airway reflexes and hemodynamic responses to tracheal extubation during rhinoplasty: A double-blind, randomized, controlled study. Curr Ther Res Clin Exp. 2009;70(3):209-20.

7. Elvan EG, Oc B, Uzun S, Karabulut E, Coskun F, Aypar U. Dexmedetomidine and postoperative shivering in patients un dergoing elective abdominal hysterectomy. Eur J Anaesthesiol. 2008;25(5):357-64.

8. Tan JA, Ho KM. Use of dexmedetomidine as a sedative and analgesic agent in critically ill adult patients: a meta-analysis. Eur J Anaesthesiol. 2010;28:3-6.

9. Jones GM, Murphy CV, Gerlach AT, Goodman EM, Pell LJ. Highdose dexmedetomidine for sedation in the intensive care unit: an evaluation of clinical efficacy and safety. Ann Pharmacother 2011;45(6):740-7.

10. Solanki SL, Bharti N, Batra YK, Jain A, Kumar P, Nikhar SA. The analgesic effect of intrathecal dexmedetomidine or clonidine, with bupivacaine, in trauma patients undergoing lower limb surgery: a randomised, double-blind study. Anaesth Intensive Care. 2013;41(1):51-6.

11. Shukla D, Verma A, Agarwal A, Pandey HD, Tyagi C. Comparative study of intrathecal dexmedetomidine with intrathecal magnesium sulfate used as adjuvants to bupivacaine. J Anaesthesiol Clin Pharmacol. 2011;27(4):495-9. 
12. Gupta M, Shailaja S, Hegde KS. Comparison of intrathecal dexmedetomidine with buprenorphine as adjuvant to bupivacaine in spinal asnaesthesia. J Clin Diagn Res. 2014;8(2):114-7.

13. Mahendru V, Tewari A, Katyal S, Grewal A, Singh MR, Katyal R. A comparison of intrathecal dexmedetomidine, clonidine, and fentanyl as adjuvants to hyperbaric bupivacaine for lower limb surgery: A double blind controlled study. J Anaesthesiol Clin Pharmacol. 2013;29(4):496-502.

14. El-Hennawy AM, Abd-Elwahab AM, Abd-Elmaksoud AM, El-Ozairy HS, Boulis SR. Addition of clonidine or dexmedetomidine to bupivacaine prolongs caudal analgesia in children. BrJ Anaesth. 2009;103(2):268-74.

15. Saadawy I, Boker A, Elshahawy MA, Almazrooa A, Melibary S, Abdellatif AA, et al. Effect of dexmedetomidine on the characteristics of bupivacaine in a caudal block in pediatrics. Acta Anaesthesiol Scand. 2009;53(2):251-6.

16. Campagnol D, Teixeira Neto FJ, Giordano T, Ferreira TH, Monteiro ER. Effects of epidural administration of dexmedetomidine on the minimum alveolar concentration of isoflurane in dogs. Am J Vet Res. 2007;68(12):1308-18.

17. Elhakim M, Abdelhamid D, Abdelfattach H, Magdy H, Elsayed A, Elshafei M. Effect of epidural dexmedetomidine on intraoperative awareness and post-operative pain after one-lung ventilation. Acta Anaesthesiol Scand. 2010;54(6):703-9.

18. Selim MF, Elnabtity AM, Hasan AM. Comparative evaluation of epidural bupivacaine - dexmedetomidine and bupivacaine -fentanyl on Doppler velocimetry of uterine and umbilical arteries during labor. J Prenat Med. 2012;6(3):47-54.
19. Abdallah FW, Brull R. Facilitatory effects of perineural dexmedetomidine on neuraxial and peripheral nerve block: a systematic review and meta-analysis. BrJ Anaesth. 2013;110(6):915-25.

20. Mirkheshti A, Saadatniaki A, Salimi A, Manafi Rasi A, Memary E, Yahyaei H. Effects of dexmedetomidine versus ketorolac as local anesthetic adjuvants on the onset and duration of infraclavicular brachial plexus block. Anesth Pain Med. 2014;4(3):e22651.

21. Nagasaka Y, Machino A, Fujikake K, Kawamoto E, Wakamatsu M. [Cardiac arrest induced by dexmedetomidine]. Masui. 2009;58(8):987-9.

22. Bharati S, Pal A, Biswas C, Biswas R. Incidence of cardiac arrest increases with the indiscriminate use of dexmedetomidine: a case series and review of published case reports. Acta Anaesthesiol Taiwan. 2011;49(4):165-7.

23. Klinger RY, White WD, Hale B, Habib AS, Bennett-Guerrero E. Hemodynamic impact of dexmedetomidine administration in 15,656 noncardiac surgical cases. J Clin Anesth. 2012;24(3):212-20.

24. Konakci S, Adanir T, Yilmaz G, Rezanko T. The efficacy and neurotoxicity of dexmedetomidine administered via the epidural route. Eur J Anaesthesiol. 2008;25(5):403-9.

25. Sanders RD, Sun P, Patel S, Li M, Maze M, Ma D. Dexmedetomidine provides cortical neuroprotection: impact on anaestheticinduced neuroapoptosis in the rat developing brain. Acta Anaesthesiol Scand. 2010;54(6):710-6.

26. Celik F, Gocmez C, Kamasak K, Tufek A, Guzel A, Tokgoz O, et al. The comparison of neuroprotective effects of intrathecal dexmedetomidine and metilprednisolone in spinal cord injury. Int J Surg. 2013;11(5):414-8. 